\title{
Some problems of high speed travel
}

\author{
D. C. READER \\ B.Sc., M.B., B.S., M.R.C.S., Ph.D. \\ RAF Institute of Aviation Medicine, Farnborough, Hants
}

\begin{abstract}
Summary
Some aspects of high speed flight are examined to investigate whether increase in speed implies any lowering of safety standards. The problem of circadian dysrhythmia is discussed and methods of attenuating its effects are explained and some new hypnotic drugs are mentioned. The risk of decompression has been quantified and predictions have been made for risks in commercial service. Cosmic radiation in supersonic aircraft is unlikely to limit commercial operation or significantly increase risks to passengers and crew. The supersonic boom is likely to limit the terrain over which supersonic aircraft can operate and regulations covering engine noise on the ground could restrict some flights.
\end{abstract}

\section{Introduction}

This paper will examine some civil problems affecting both crew and passengers of high speed aircraft. It used to be a 6-8 week sea cruise by liner to Australia but in 1974 one can fly from London to Sydney in $28 \frac{1}{2} \mathrm{hr}$. When Concorde starts operating commercially, the flight time is expected to be $15 \mathrm{hr}$. Then New York will be only $3 \frac{1}{2} \mathrm{hr}$ away and Buenos Aires $9 \frac{1}{2} \mathrm{hr}$ away, flying at Mach $2 \cdot 2$ (1350 m.p.h.). Travel at this speed will accentuate some of the problems experienced in jet aircraft in 1974. Probably the most widespread of these is circadian dysrhythmia, colloquially called 'jet lag'.

\section{Circadian dysrhythmia}

Circadian dysrhythmia is caused by the desynchronization of the normal sleep and wakefulness cycle of the body with local time. The problem presents itself to travellers as lowered efficiency and malaise, the inability to sleep during local sleeping hours after a journey and fatigue when one is required to be alert. This problem is even more pressing for the crew who have to rest in an allotted time so as to be fit to fly the aircraft again.

Physiologically there is good evidence for an endogenous circadian rhythm (Mills, 1966). The rhythm persists under constant conditions of light and dark, e.g. underground, and the rhythm tends to persist even when new phases or cycles are imposed. Circadian rhythm is acquired early in infancy and persists with some changes throughout life. It affects practically the whole physiological machine $\underset{\omega}{\omega}$ respiration, thermal regulation, cardiovascular func=o tion, adrenocortical activity, the reticulo-endothelia and renal systems, even the parasites we may have inir our bodies respond to our own circadian rhythm. Pathology also follows a rhythm, mortality rate is highest very early in the morning and psychotic ${ }_{\infty}$ episodes show inherent periodicity. With such $a_{\infty}^{+}$ widespread control on so many functions, littleo wonder that well-being is easily lost when one's? circadian rhythm is forced to change.

How can one minimize these effects? Passengers should start long journeys well rested and emplaning ${ }_{3}^{\mathbb{D}}$ drills should be minimized, vaccinations and other medical procedures should be completed some $2^{-}$ weeks before the journey. Smoking and alcohis $\overrightarrow{0}$ ingestion in flight should be minimized and ondy light meals taken. The appropriate clothing shoufdo be worn and passengers should be encouraged to sleep when possible by the extinction of lights. At the destination, one should allow at least a day or a full night to permit some acclimatization to the $\frac{\curvearrowright}{\otimes}$ local time and the knowledge that physical fatigue

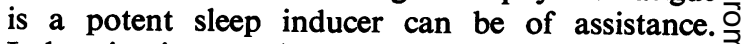
Indoctrination on the hazards of circadian dysrhythmia can help but this aspect is seldom mentioned.

With crews, lack of sleep can become cumulative. Preston, Ruffell-Smith and Sutton-Mattocks (1973) found progressive sleep loss in cabin crews on long flights, and older personnel tended to lose sleep more 3 than others. Transmeridian routes were more likely to produce gross sleep disruption and sleep periods soon became fragmented. The authors found that $\mathrm{O}$ hotel managements could assist in serving breakfast in the evening, dinner in the morning and by avoiding disturbance from hotel cleaning staff, sleep was not disrupted. One solution for this problem is to $\sigma$ base crews abroad for periods of up to 3 months but $N$ this has drawbacks usually of a managerial or trade union nature.

The use of hypnotics is more contentious. It has been shown (Borland and Nicholson, 1974; 1975; Borland, Nicholson and Wright, 1974) that nitraze- $\stackrel{\mathcal{Q}}{+}$ pam (mogadon) is not a drug of choice for aircrew as it has a long half-life ( $30 \mathrm{hr})$, and one can 
demonstrate residual effects on skilled performance some $19 \mathrm{hr}$ after the ingestion of $10 \mathrm{mg}$. Flurazepam (dalmane), although it has a shorter half-life, also has residual effects for $16 \mathrm{hr}$ after the ingestion of $30 \mathrm{mg}$. Heptabarbitone (medomin, $200 \mathrm{mg}$ ) and methaqualone (melsedin, $150 \mathrm{mg}$ ) are better, but not without some disadvantages. Heptabarbitone is a barbiturate with a short half-life $(10 \mathrm{hr})$, and does affect performance for at least this period. Methaqualone is excreted at a variable rate but can persist for $10 \mathrm{hr}$ and affect reaction time, although little effect on skilled performance can be demonstrated $10 \mathrm{hr}$ after ingestion. It is better for aircrew to try to sleep without the use of hypnotics or alcohol but, if drugs must be used, heptabarbitone and methaqualone are probably the best to use, after an adequate trial has been instituted off duty. For passengers the problems are less severe and some non-habit-forming hypnotic could be used with good effect to alleviate the fatigue of long aircraft journeys.

\section{High altitude}

In order to fly fast, aircraft must fly high where the air density and aerodynamic drag are less. Modern jet aircraft cruise just below the tropopause $(38,000$ $\mathrm{ft}$ ) but supersonic aircraft will fly considerably higher, up to $60,000 \mathrm{ft}$. At this altitude loss of cabin pressure is likely to be more dramatic. Breathing $100 \%$ oxygen will give protection up to $40,000 \mathrm{ft}$ and above this altitude, oxygen under pressure must be administered to maintain oxygenation. At $63,000 \mathrm{ft}$ oxygen at a high pressure is required with counter pressure to the body by means of a special garment. With a pressure in the cabin equivalent to $8,000 \mathrm{ft}$ altitude, the sequelae of explosive decompression caused by defects in the cabin walls were examined by Nicholson and Ernsting (1967). Assuming that the aircraft had initiated a descent one minute after cabin pressure was lost, a 4-in. diameter hole would cause the cabin altitude to rise to $30,000 \mathrm{ft}$. This is unlikely to be serious; transient unconsciousness could occur if oxygen was not breathed immediately, but consciousness would soon be regained on the descent. With a 6-in. diameter hole, the cabin altitude would rise to $42,500 \mathrm{ft}$ and the altitude would exceed $25,000 \mathrm{ft}$ for $6 \frac{1}{2} \mathrm{~min}$. If oxygen was administered immediately, severe hypoxia would be avoided although unconsciousness would be likely. With an 8 in. diameter hole, the cabin altitude would rise to $53,500 \mathrm{ft}$ and would be above $25,000 \mathrm{ft}$ for $7 \frac{1}{2} \mathrm{~min}$ and above $40,000 \mathrm{ft}$ for 4 minutes. The risk to passengers in the 8-in. diameter hole case would be considerable as the time at altitude is sufficient to cause severe hypoxia which could be fatal, even if oxygen was administered immediately.

These predictions were tested by exposing animals to similar decompression profiles as would occur in a supersonic aircraft with these defects in the cabin wall. With a 4-in. diameter hole, the animals became unconscious but made a normal recovery. With the 6-in. diameter hole, unconsciousness supervened early at $40,000 \mathrm{ft}$ and three of the four animals either succumbed then or died later. The animals that survived initially showed gross neurological and behavioural abnormalities before death which suggested widespread brain damage. With the 8-in. diameter hole, the animals failed to recover.

The requirements for the Concorde state that cabin altitude should not exceed $15,000 \mathrm{ft}$ following a failure in the pressurization system which would occur once in $10^{3}-10^{5}$ flying hours. The cabin altitude should not exceed $25,000 \mathrm{ft}$ after a remote failure ( 1 in $10^{5}-10^{7}$ flying $\mathrm{hr}$ ) and should only exceed 25,000 after an extremely remote failure (less than 1 in $10^{7}$ flying hr). Recent investigations into the integrity of the Concorde fuselage indicate that the failures which are likely to be hazardous will be extremely remote (Preston, 1972). Multiple air supplies to the cabin together with small discharge valves and small diameter windows (less than 6 in diameter) should further safeguard the passengers. For the crew, special quick donning mask assemblies that will supply oxygen at high pressure have been devised and these will maintain the oxygenation of the crew so that the appropriate descent manoeuvres can be executed. The passengers will be supplied with drop-down oxygen masks automatically lowered when the pressure in the cabin falls below the equivalent of $14,000 \mathrm{ft}$.

\section{Radiation}

The atmosphere functions as an extremely efficient attenuator of the most harmful radiation that strikes the earth. Galactic radiation consists of high energy particles (protons and helions) and heavy particles (Fe., Mg., etc.) These normally disintegrate as they meet the upper atmosphere and few reach the surface. The distribution of cosmic radiation is affected by the earth's magnetic field, thus the density of the radiation is greatest at the magnetic poles. Crew and passengers on supersonic aircraft at altitudes above $60,000 \mathrm{ft}$ could run some risk of radiation, albeit very slight. It has been estimated that an average dosage of $1.5 \mathrm{mrem} / \mathrm{hr}$ can be expected on transatlantic routes. Trans-Siberian routes would involve flights at $79^{\circ}$ north where $1.55 \mathrm{mrem} / \mathrm{hr}$ or 3.9 $\mathrm{mrem} /$ flight would be expected.

Solar flares occur in cycles and produce X-rays which are difficult to screen in aircraft. Warnings of intense solar activity are given by observatories and other forecasting centres and the aircraft will carry radiation meters which will monitor the ambient radiation received by the aircraft and occupants 
so that changes in radiation should not remain undetected. Exposure rates in excess of $10 \mathrm{mrem} / \mathrm{hr}$ will alert the crew and $50 \mathrm{mrem} / \mathrm{hr}$ will require descent to lower altitudes (Preston, 1972).

The International Commission on Radiation Dosage advises a limit of $5 \mathrm{rem} /$ year and a maximum of $3 \mathrm{rem}$ in any three months for radiation workers, and $0.5 \mathrm{rem} /$ year for others (Preston, 1972). This allows almost sixty round trips per year on the Atlantic route which is unlikely to be exceeded by many passengers. Aircrew are at a greater risk, and it has been estimated that a pilot achieving 160 return flights on the Atlantic route could accumulate a dose of $1.3 \mathrm{rem}$ in one year, which is well below the limit for radiation workers although it is above the level for the general public. Stewardesses who become pregnant are not normally allowed to work after the third month. Thus the fetal radiation is unlikely to exceed $1 \mathrm{rem}$. Crews may have to wear film badges and undergo blood tests, as do workers where there is a risk of radiation, but radiation is unlikely to hamper supersonic transport operations.

\section{Noise}

For passengers of supersonic aircraft the flight is likely to be smooth and quiet. However, when the aircraft is travelling at supersonic speed an area of 50 miles wide underneath the flight path will be subjected to the additional disturbance of the supersonic boom. When cruising at altitude, the disturbance will be slight but this can increase in intensity when the aircraft accelerates or turns and boom over-pressures of $3.6 \mathrm{lb} / \mathrm{ft}^{2}$ have been predicted. The effects of the sonic boom have been investigated by many workers and the data have been summarized by the Sonic Boom Panel of the International Civil Aviation Organization (1970).

The sonic boom is unlikely to damage the ear, nor is it likely to cause chronic physiological effects. Eardrums can be ruptured with explosions having an over-pressure of $150 \mathrm{lb} / \mathrm{ft}^{2}$ and aural damage is unlikely below this figure. Tinnitus can occur with over-pressures of $95 \mathrm{lb} / \mathrm{ft}^{2}$ and hearing loss has been reported above $30 \mathrm{lb} / \mathrm{ft}^{2}$. The 'startle' effect of sonic booms can be annoying and tests of sonic booms at the rate of $10-15 /$ day on a community unrelated to aviation showed that $100 \%$ of the population found the booms unacceptable when the over-pressures were $3.6 \mathrm{lb} / \mathrm{ft}^{2}$. When the over-pressures were reduced to $2 \mathrm{lb} / \mathrm{ft}^{2}$, only $40 \%$ deemed them unacceptable. Sleep was interrupted, for old persons more so than for the young, infants were alarmed but children were seldom disturbed in these tests. Community reactions usually centred around the fear of damage to property and were also related to the degree of news media coverage.
The effect on property in these tests was slight an was confined to extension of plaster and paint cracks and broken glass windows. The damage claims for broken glass was in the order of 1 claim for $10^{\mathrm{F}}$ population per flight but only a third of those claims were judged valid.

In other tests directed at Oklahoma City, Chicag产. and St Louis, U.S.A., the paid claims amounted to $\$ 220$ per $10^{6}$ boom-person exposures. Older propert deteriorated faster but it was difficult to correlate the hazard of sonic booms with those of the loca $\vec{D}$ environment, e.g. heavy lorries, etc.

Sonic booms on animals showed a range of effects from minor startle reactions in cattle to pandemono ium and crowding in chickens. There were ng measurable effects on egg or milk production or foot consumption.

The likelihood of sonic booms starting avalancheg of snow is thought to be low.

It has been recommended that the effects of soni booms on sleep, sick and aged people and persons at sea should be further investigated. Clearly much. more work is required before supersonic aircraft are allowed to fly over populated areas.

In this paper, a few aspects of high speed trave have been examined in order to answer the question whether travel is safe. The yearning to fly faster and go further in less time will always be with us, Fute this should never imply less safety. One of the safestr ways to travel is by air and supersonic flight showid be as safe as subsonic flight.

\section{Acknowledgments}

The author is indebted to the Director General of Medica五 Services (RAF) for permission to publish this paper.

\section{References}

BorlaND, R.G. \& Nicholson, A.N. (1974) Human per formance after a barbiturate (heptabarbitone). British. Journal of Clinical Pharmacology, 1, 209.

Borland, R.G. \& Nicholson, A.N. (1975) Comparison op the residual effects of two benzodiazepines (nitrazepani and flurazepam hydrochloride) and pentobarbitone sodium on human performance. British Journal of Clinicah Pharmacology, 2, 9.

Borland, R.G., Nicholson, A.N. \& Wright, Catherine M? (1974) Behavioural sequelae of Methaqualone in man ando in the monkey (Macaca mulatta). British Journal of Clinica?
Pharmacology, 2, 131 .

International Civil Aviation Organization, Sonic Boom Panel (1970) Report of Second Meeting, Montreal, Canada.N Document 8894 SPP/II.

Mills, J.N. (1966) Human circadian rhythms. Physiological Reviews, 46, 128.

Nicholson, A.N. \& ERNsting, J. (1967) Neurological N sequelae of prolonged decompression. Aerospace Medicine 38, 4.

Preston, F.S. (1972) Medical aspects of supersonic travel. $\stackrel{0}{\frac{1}{C}}$ Proceedings of the Royal Society of Medicine, 2, 187.

Preston, F.S., RUfFel-Smith, H.P. \& Sutton-Mattocks, V. (1973) Sleep loss in air cabin crew. Aerospace Medicine, 44, $\square$ 8, 931 . 